\title{
EDITORIAL
}

\section{Small airways, big challenge}

\author{
P.J. Sterk and E.H. Bel
}

$\mathbf{R}$ espiratory medicine has always been in a privileged position, because it has relatively easy access to its organ of interest. Chest radiographs have been one of the earliest widely adopted imaging techniques in medicine, whilst quantitative pulmonary function methods have generally been available for more than three quarters of a century. Add to this the sophisticated bronchoscopic inspection, sampling and intervention techniques, the modern molecular analysis of exhaled air and the direct topical administration of drugs: what else could one desire in terms of diagnosis, monitoring and therapy? Whilst cardiologists and nephrologists were struggling to obtain a close picture of their favourite organs in their patients, the pulmonologists had the luxury of having access to valuable information about pathology, physiology and cell function in lung disease.

However, do we really know what is going on in the lung in health and disease? The lung is a complex, adaptive organ in terms of its anatomy [1], mechanics [1, 2], gas transport [1, 3] and cell biology [1,4]. All these features turn out to be highly dynamic, balancing under delicate homeokinetic conditions [5]. Any shifts in such dynamics can readily lead to manifest disease [6], which may be captured by measuring the temporal behaviour of the lung $[7,8]$. However, most of these critical events take place in the lung periphery: the small airways and alveolar region. This is the key area that determines the transition from physiologic to pathophysiologic behaviour of the lungs. And we have not been able to get direct access to this area yet.

In the current issue of the European Respiratory Review, BURGEL [9] addresses the role of small airways in obstructive airway disease. His article is based on an ERS Research Seminar held in Amsterdam in October 2010. This meeting was largely based on prolonged discussions amongst experts in the field following very concise introductions in each of fields, such as the pathology, physiology, imaging, biology, diagnostic relevance and therapeutic targeting of the small airways in asthma and COPD. The aim was to exchange the best of our knowledge and to identify the major unexplored areas that are required for understanding the role of small airways in disease. The interdisciplinary nature of the seminar was considered to be a conditio sine qua non.

Dept of Respiratory Medicine, Academic Medical Centre, University of Amsterdam, Amsterdam, The Netherlands.

CORRESPONDENCE: P.J. Sterk, Dept of Respiratory Medicine, F5-259, Academic Medical Centre, P.0. Box 22700, NL-1100 DE, Amsterdam, The Netherlands. E-mail: p.j.sterk@amc.nl

PROVENANCE: Submitted article, peer reviewed.
P-R. Burgel has succeeded in creating a very comprehensive, state-of-the-art article about the small airways. It reads as an adventure, confronting us with the uneasy feeling that we don't know much about this vital part of the lungs after all. Is there a lack of data? Not really, but what appears is that the various studies available all had to compromise in the selection of patients of interest and sampling techniques. The pathologists are providing excellent data on post mortem or resection material, but can't get hold of the regular asthma or chronic obstructive pulmonary disease patients of interest. The physiologists are presenting very smart techniques, but have to admit that these are all indirect measures of small airways function. The radiologists are increasing their resolution when measuring structure and function of the lung, but still can't get close enough to the small airways in vivo. And the molecular biologists cannot simply get hold of the cells in the small airways, or of the RNA and protein profiles that seem to be critical in the lung periphery.

Hence, what then can we expect from the clinicians? The article by BURGEL [9] constantly refers to potential clinical implications, making us all very modest in terms of the potential of respiratory medicine. Apparently, the lung is still mainly a black box, and clinicians are constantly challenged to give their best guess on the extent and implications of any abnormalities in the lung periphery. The article by BURGEL [9] clearly shows that this provides many (novel) research opportunities. For instance, there is much mileage in determining the prognostic significance of small airways abnormalities, or in establishing whether local pathogens are driving small airway pathology and disease. And eventually, there is much room for improvement in targeting the right therapy to the small airways.

There is no doubt that solving this requires integrative approaches, in which local cellular phenotyping at the RNA, protein or metabolome level is linked to morphology by modern imaging, to small airways function and eventually to clinical status [10]. This seems to be the single way out, and we are quite fortunate that exactly this is actually emerging [11]. It may be called "systems medicine", which is today's phrase for high throughput, computational (patho)physiology allowing integrative, individual phenotyping in disease. Let respiratory medicine take the lead again, by adopting this strategy when unravelling the role of the "silent zone" in lung disease.

Much of the data discussed by P-R. Burgel has been produced by the big giants of the small airways. Let us say the somewhat older, ever-youngsters in the field. The article nicely shows that the field is wide open for new and young giants, who can eventually put the small airway puzzle together. 


\section{STATEMENT OF INTEREST}

P.J. Sterk has received investigator-initiated grants (paid to his institution) by European Union and EFPIA (IMI), GlaxoSmithKline and Philips Research. E.H. Bel has received consultancy fees (paid to her institution) from Actelion, PDL-Pharma, Merck and Shering Plough. She has received advisory board fees (paid to her institution) from Novartis and has received lecture fees (each paid to her institution) from Aerocrine, Nycomed and GlaxoSmithKline. She has received industry sponsored grants (each paid to her institution) from Cambridge Antigen Technology, Novartis and European Union/EFPIA.

\section{REFERENCES}

1 Weibel ER. The Pathway of Oxygen. Structure and Function in the Mammalian Respiratory System. Cambridge, Harvard University Press, 1984

2 Otis AR, McKerrow CB, Bartlett A, et al. Mechanical factors in distribution of pulmonary ventilation. J Appl Physiol 1956; 8: 427-443.

3 Cotes JE, Chinn DJ, Quanjer $\mathrm{PhH}$, et al. Standardization of the measurement of transfer factor (diffusing capacity). Report
Working Party Standardization of Lung Function Tests European Community for Steel and Coal. Eur Respir J 1993; 6: Suppl. 1, 641-652.

4 Barnes PJ. Immunology of asthma and chronic obstructive pulmonary disease. Nature Rev 2008; 8: 183-192.

5 Macklem PT. Emergent phenomena and the secrets of life. J Appl Physiol 2008; 104: 1844-1846.

6 Gunst SJ, Fredberg JJ. The first three minutes: smooth muscle contraction, cytoskeletal events, and soft glasses. J Appl Physiol 2003; 95: 413-425.

7 Frey U, Suki B. Complexity of chronic asthma and chronic obstructive pulmonary disease: implications for risk assessment, and disease progression and control. Lancet 2008; 372: 1088-1099.

8 Muskulus M, Slats AM, Sterk PJ, et al. Fluctuations and determinism of respiratory impedance in asthma and chronic obstructive pulmonary disease. J Appl Physiol 2010; 109: 1582-1591.

9 Burgel P-R. The role of small airways in obstructive airway diseases. Eur Respir Rev 2011; 20: 23-33.

10 Hogg JC. Pathophysiology of airflow limitation in chronic obstructive pulmonary disease. Lancet 2004; 364: 709-721.

11 Auffray A, Chen Z, Hood L. Systems medicine: the future of medical genomics and health care. Genome Med 2009; 1: 2. 